\title{
Benificial Uses and Antimicrobial Activity of Phyllanthus Emblica, Achyranthes Aspera and Allium Sativum- A Mini Review
}

\author{
Zakaria Ahmed ${ }^{1,}$ Ummey Nahor $^{2}$ \\ ${ }^{1,2}$ Department of Microbiology, Primeasia university, HBR Tower, 9 Banani, Dhaka-1213, Bangladesh.
}

\begin{abstract}
World Health Organization appreciated the importance of medicinal plants for public health care in developing nations. Different parts of Phyllanthus emblica, Achyranthes aspera and Allium sativum plants have important medicinal role in human health. This review is indicate that plants have the potential to generate herbal metabolites and the crude extracts demonstrating antimicrobial activity could result in the discovery of new chemical classes of antibiotics that could serve as selective agents for the maintenance of animal or human health and provide biochemical tools for the study of infectious diseases.
\end{abstract}

Key words: Antimicrobial activity, Amloki, Bely asra and Garlic.

\section{Introduction}

Bioactive compounds from diverse sources have been isolated and characterized around the world. Systematic screening of plant materials represent an important effort to find new bioactive compounds with the needed therapeutic potential to fight against pathogenic microorganisms particularly with respect to those that are hospital based. Nature has been a source of medicinal agents for thousands of years and an impressive number of modern drugs have been isolated from natural sources. During the last two decades there has been an up search in search for new plant derived drugs containing the medically useful alkaloids, glycosides, polyphenolics, steroids and terpenoids derivatives. Plants used for traditional medicine contain a wide range of substances that can be used to treat chronic as well as infectious diseases. Clinical microbiologists have great interest in screening of medicinal plants for antimicrobial activities and phytochemicals as potential new therapeutics. Researchers identified 119 secondary metabolites isolated from the plant that are being used globally as drugs. It has been estimated that $80 \%$ of the world's population still use the traditional medicines for their primary health care needs. Many important modern plant drugs such as the winblastin and wincristiene have been discovered by following from traditional medicines (Raghu and Ravindra 2010). In the indigenous cultures higher plants have formed the basis for the treatment of the diseases since the earliest time. Accuracy in recording or observing the medical use of a plant determining whether the ethanomedicinal use can be demonstrated under the specific condition in the laboratory (Ghosh et al 2008). Chemical characterization of the compounds and the role of the placebo effect are important issues that need to be verified in the development of drugs of

*Corresponding Author; Department of Microbiology, Primeasia university.

plant origin (Raghu and Ravindra 2010). The one of the largest group of chemical produced by plants are the alkaloids and their amazing effect on humans has let to the development of powerful pain killer medications (Egwaikhinde et al 2008, Raffauf 1996). The dried fruits have a good effect on hair hygiene and have long been respected as an ingredient of shampoo and hair oil (Thakur et al 1989). Acalypha indica (Euphorbiaceae), Aerva lanata, Juss.ex Schult (Amaranthaceae), Phyllanthus amarus (Euphorbiaceae), Phyllanthus emblica. (Euphorbiaceae), Cassia auriculata (Caesalpiniaceae) and Caesalpinia pulcherrima $\mathrm{Sw}$ (Caesalpiniaceae) have high medicinal properties and active compounds (Pranithanchai et al 2009, Rao et al 2005, Schiebinger 2004). The antibacterial studies of the above medicinal plants were already investigated against some common human pathogenic bacteria (Anushia et al 2009). Population rise, inadequate supply of drugs, prohibitive cost of treatments, side effects of several allopathic drugs and development of resistance to currently used drugs for infectious diseases have led to increased emphasis on the use of plant materials as a source of medicines for a wide variety of human ailments. Global estimates indicate that $80 \%$ of about 4 billion population cannot afford the products of the Western Pharmaceutical Industry and have to rely upon the use of traditional medicines, which are mainly derived from plant material (Brindha et al, 2008). Practitioners of traditional medicine believe that the constituents of plants are unique as they contain both active ingredients and "non-active" components that play a role in enhancing the well-being of their patients (Ureghe et al 2010). 


\section{AMLOKI (Phyllanthus emblica)}

The plant genus phyllanthus (Euphorbiaceae) is widely distributed in most of tropical and subtropical countries. P. emblica has been used for the anti-inflammatory and anti-pyretic treatments by the rural population and has been used for the treatment of several disorders such as the Scurvy, Cancer and Heart diseases. The important constituent of plant leaves have the anti-neutrophilic activity and anti-platelet properties in vitro. The extracts also posses several pharmacological properties like anti-viral (HIV, AIDS, Herpes Virus, CMV) antimutagenic, anti-allergic, anti-bacterial activities (Raghu and Ravindra 2010, Khopde et al 2000). P. emblica contains different class of secondary metabolites (Calixto et al 1998). The phytochemical analysis of $P$. emblica reveals the presence of alkaloids, tannins and saponins. These compounds are known to be biologically active. Tannins have been found to form irreversible complexes with proline-rich proteins (Raghu and Ravindra 2010) resulting in the inhibition of the cell protein synthesis. Apart from antimicrobial activity exhibited by tannins, they also react with proteins to provide the typical tanning effect. Medicinally, this is important for the treatment of inflamed or ulcerated tissues (Raghu and Ravindra 2010). Tannins have important roles such as stable and potent antioxidants. Herbs that have tannins as their main component are astringent in nature and are used for treating intestinal disorders such as diarrhoea and dysentery (Dharmananda 2003). Medical studies conducted on P. emblica fruit suggest that it has antiviral properties (Udupa 1985) and also functions as an antibacterial and anti-fungal agent (Treadway 1994). The use of amla as an antioxidant has been examined by a number of authors (Bhattacharya et al 1999, Chaudhuri 2004). . Experiments conducted at the Niwa Institute of immunology in Japan had shown P. emblica to be a potent scavenger of free radicals where it was found that $P$. emblica preparations contained high levels of the free-radical scavenger, superoxide dimutase (SOD), in the experimental subjects (Treadway 1994). Emblica was shown to reduce UV-induced erythema and had excellent free-radical quenching ability, chelating ability to iron and copper as well as MMP-1 and MMP-3 inhibitory activity (Chaudhuri 2004). The juice of the bark of $P$. emblica combined with honey and turmuric is a remedy for gonorrhoea (Nadkarni and Nadkarni 1999). The expressed juice of $P$. emblica along with other ingredients is used to cure fits and insanity (Jayaweera 1980). In Indonesia, the pulp of this fruit is smeared on the head to dispel headache and dizziness caused by excessive heat (Perry, 1980). On the other hand, it can be used for anointing and "cooling" the head by mixing with buttermilk (Treadway 1994). P. emblica has been used for anti-inflammatory and antipyretic treatments by rural populations in its growing areas. $P$. emblica powder is mixed with red sandalwood (Pterocarpus santalinum) and prepared in honey to relieve nausea and vomiting (Treadway 1994). Tang et al (2009) investigated the antimicrobial spectrum and activities of $70 \%$ ethanol extract of $P$. emblica fruits and the results indicated that the extract shows little antimicrobial activity against tested mold, but it has certain antimicrobial activity against Saccharomyces cerevisiae with a MIC of 8.0\%, and presents strong antimicrobial activities against Bacillus stearothermophilus, Bacillus proteus, Staphylococcus aureus, Escherichia coli and Bacillus subtilis in turn with MICs of $2.0 \%, 2.0 \%, 2.0 \%, 4.0 \%$, and $4.0 \%$, respectively. P. emblica can be used medicinally for the treatment of diarrhoea. Raghu and Ravindra (2010) stated that $P$. emblica fruits have been used for various disorders. According to their findings, P. emblica methanolic extract exhibited a significant antimicrobial activity where the MIC exhibited against the gram positive and negative microbes ranges between 0.261 to 0.342 . The expressed juice of the fruit along with other ingredients is used to cure cough, hiccough, asthma and other diseases (Jayaweera 1980). Chaudhuri (2004) reported the effectiveness of a standardized antioxidant fraction of $P$. emblica as a skin lightener. $P$. emblica is also used as a febrifuge, as an anti-inflammatory, anti-diuretic and preventive tonic against loss of hair (Tsarong 1994). Xiaoli et al (2009) first reported on the in vitro antimicrobial and antioxidant properties of supercritical fluid extraction (SFE) and methanolic extracts prepared from $P$. emblica where they introduced a unique natural source that possesses strong antimicrobial and antioxidant substances. The SFE extract had a strong and broad spectrum of antimicrobial activity, and in some cases, even found to have similar activity to the antibiotics ampicillin and nystatin. On the other hand, the methanolic extract exhibited quite strong antioxidant activities, which were found to be similar, and in some cases even higher than the reference compound butylated hydroxytoluene (BHT).

\section{BELY ASRA (Achyranthes aspera)}

Achyranthes aspera belongs to the family-Amaranthaceae. It is an annual, stiff erect herb, and found commonly as a weed and used by traditional healers for the treatment of fever, dysentery and diabetes (Girach and Khan 1992, Liersch 1992). Leaf decoction for cardiovascular toxicity has been reported (Han and Un 2003), and the ethanol crude extract showed high larvicidal activity on the tick larvae against Boophilis microplus (Chungsamarnyart et al 1991). The root extract is well reputed for its pronounced insect molting hormonal activity and the ethanolic extract of the leaves and stem of the plant inhibited the growth of Bacillus subtilis and Staphylococcus aureus bacterial strains (Valsaraj et al 1997). Roots are used as astringents to wounds, in abdominal tumor and stomach pain (Ghani 2003). The benzene extract of the stem bark shows abortifacient activity in the rat (Bhattarai 1994). Leaf extracts were reported to posses thyroid stimulating, 
antiperoxidative and antifungal activity properties.(Tahiliani 2000, Elumalaii et al 2009). The aqueous and methyl alcohol extracts of the plant also decreased blood glucose levels in normal and alloxan diabetic rabbits (Akhtar and Iqbal 1991). It is reported to contain alkaloids, flavonoids, saponins, steroids and terpenoids. The water soluble alkaloid achyranthine isolated from Achyranthes aspera possess anti-inflammatory activity (Sutar et al 2011). A. aspera is a perennial herb growing upto three meters. Juice of A. aspera root is used in the treatment of diabetes, juice from leaf is used to treat earache (Chopra et al 1986). Several investigators have reported that the methanolic extracts of leaves Achyranthes aspera has significant antimicrobial activity against the Gram-Positive (S. aureus, B. subtilis), Gram-negative bacterial (K. pneumoniae, E. coli) and fungal species (A. niger, C. albicans) (Ramesh et al 2011). It is also used in the treatment of gonorrhea. The whole part of the plant is claimed to posses medicinal properties in the traditional medicinal system. Extracts from this plant is given to cure diabetics in mammals. Phytochemical or biological works were scanty in A. aspera (Torssel 1993). There are scanty reports on its antibacterial activities of this plant. In order to demonstrate the antibacterial efficacy, test were conducted against human pathogenic bacteria including those responsible for causing inflammation. The plant is used in indigenous system of medicine as emenagogue, antiarthritic, antifertility, laxative, ecbolic, abentifacient, anti-helminthic, aphrodisiac, antiviral, anti-plasmodic, antihypertensive, anti-coagulant, diuretic and anti-tumor (Anonymous 1985). It is also useful to treat cough, renal dropsy, fistula, scrofula, skin rash, nasal, infection, chronic malaria, impotence, fever, asthma, piles and snake bites (Selvanayagam et al. 1994). The root is astringent, diuretic and antispasmodic. It is used in the treatment of dropsy, rheumatism, stomach problems, cholera, skin diseases and rabies (Manandhar 2002). The juice extracted from the root of this plant, mixed along with the root extracts of Urena lobata and the bark of Psidium guajava, are used in the treatment of diarrhoea and dysentery (Manandhar 2002). The plant is astringent, digestive, diuretic, laxative, purgative and stomachic. The juice of the plant is used in the treatment of boils, diarrhoea, dysentery, haemorrhoids, rheumatic pains, itches and skin eruptions. The ash from the burnt plant, often mixed with mustard oil and a pinch of salt, and is used as a tooth powder for cleaning teeth. It is believed to relieve pyorrhea and toothache. The leaf is emetic and a decoction is used in the treatment of diarrhoea and dysentery. A paste of the leaves is applied in the treatment of rabies, nervous disorders, hysteria, insect and snake bites. Mohinder et al (2005) stated that Chloroform and methanol root and shoot extracts of $A$. aspera showed good amount of antibacterial activity against Klebsiella sp. Elumalai et al (2009) reported that the ethanol and methanol extracts of the leaves of $A$. aspera revealed a significant scope to develop a novel broad spectrum of antifungal herbal formulation.

\section{GARLIC (Allium sativum)}

Garlic (Allium sativum) is one of those plants that were seriously investigated over the years. It has been used for centuries to fight infections (Onyeagba et al 2006). The early Egyptians used it to treat diarrhea; the ancient Greeks used it to treat intestinal and extra-intestinal diseases, while the ancient Japanese and Chinese used it to treat headache, flu, sore throat and fever. In Africa, particularly in Nigeria, it is used to treat abdominal discomfort, diarrhea, otitis media and respiratory tract infections (Ankri and Mirelman 1999, Jaber and Al-Mossawi 2007). Jehan et al (2011) stated that water extracted samples of garlic indicated a good range of inhibitory effect against Salmonella typhi and butanol extracted sample showed highest activity against Erwinia carotovora. Garlic has been shown to inhibit the growth of a variety of microorganisms, not only bacteria but also fungi and viruses. The antimicrobial activity of garlic is believed to be due to the effect of allicin, the main ingredient in garlic, generated by the phosphopyridoxal enzyme allinase (Susumu et al 1987). In investigation of the activity against other fungal and bacterial strains by Susumu et al (1987), ajoene was found strongly inhibited the growth of Candida glabrata, C. tropicalis, Trichophyton mentagrophytes, Tricosporon beigelii and Saccharomyces cerevisiae. Deresse (2011) reported that A. sativum has antimicrobial properties against $S$. aureus. It has both a bacteristatic and bactericidal activity when tested in vitro using crude preparation of garlic. Therefore, gallic may be used successfully for treating food poisoning causative agent like S. aureus. A compound, found exclusively in garlic, may control blood sugar levels just as well as insulin but without the need for daily injections (Hiromu et al 2010). Garlic has also proposed to treat asthma, candidiasis, colds and antibacterial effect against food borne pathogens like Salmonella, Shigella and Staphylococcus aureus (Teferi and Hahn 2002). Therapeutic use of garlic has been recognized as a potential medicinal value for thousands of years to different microorganisms, such as antifungal, antiviral, antibacterial antihelmantic, antiseptic and anti-inflammatory properties of garlic are well documented. Moreover, garlic extracts exhibited activity against both Gram negative (E. coli, Salmonella spp. and Citrobacter sp., Enterobacter sp., Pseudomonas sp. and Kilabsella sp.) and Gram positive (S. aureus, S. pneumonia, Group A Streptococcus and Bacillus anthrax) all of which are causes of morbidity world wide. There is extensive literature on the antibacterial effects of fresh garlic juice, aqueous and alcoholic extracts, lyophilized powders, steam distilled oil and other commercial preparations of garlic. The antibacterial effects of garlic have been studied by Reuter et al. (1996) where they found that the active inhibitory principle of garlic is allicin or diallyl thiosulphinic acid. 


\section{References}

[1]. Anushia C, Sampathkumar P and Ramkumar L (2009) Antibacterial and antioxidant activities in cassio auriculata. Global J. Pharm. 3(3): 127-130.

[2]. Akhtar MS and Iqbal J (1991) Evaluation of the hypoglycaemic effect of Achyranthes aspera J Ethnopharmacol. $31: 49$.

[3]. Ankri S and Mirelman A (1999) Antimicrobial properties of allicin from garlic. Microb. Infect. 2: $125-129$.

[4]. Anonymous (1985) The Wealth of India, Raw Materials. New Delhi: Publication and Information Directorate, Center for Scientific and Industrial Research (CSIR), p. 57.

[5]. Bhattarai N (1994) Folk herbal remedies for gynaecological complaints in Central Nepal. Int J Pharmacog. 32(1):13-26.

[6]. Brindha P, Sridharan G, Pradeep V and Sasikumar S (2008) Antitumor activity and in vivo antioxidant status of Hyptis suaveolens against Ehrich ascites Carcinoma in Swiss albino mice. Indian Drug, 45:10.

[7]. Bhattacharya A, Chatterjee A, Ghosal S and Bhattacharya SK (1999) Antioxidant activity of active tannoid principles of Emblica officinalis (amla). Indian J Exp. Biol. 37(7): 676-80

[8]. Chopra, RN, Nayar SL and Chopra IC (1986) Glossary of Indian medicinal plants. Council of Scientific and Industrial Research, New Delhi. 185-25

[9]. Chaudhuri RK (2004) Standardised extract of Phyllanthus emblica. A skin lightener with anti-aging benefits. Proceedings PCIA Conference, Guangzhou, China 9-11.

[10]. Chungsamarnyart N, Jiyajinda S and Jangsawan W (1991) Larvicidal effect of plant crude extracts on the tropical cattle tick (Boophilus microplus). Kasetsert J. 25:80-89.

[11]. Calixto JB, Antos ARS, Filho VC and Tunes RA (1998) A review of the plants of the genus phyllanthus: their chemistry, pharmacology, and therapeutic potential. J. Med. Bio. 31:225-258.

[12]. Deresse D (2011) Antibacterial effect of garlic (Allium sativum) on Staphyloccus aureus: An in vitro study. African J. Biotech. 10 (4): 666-669.

[13]. Egwaikhinde, PA, Okeniyi SO, Akporhonor EE and Emua SO (2008) Studies on bioactive metabolites constituents and antimicrobial evaluation of leaf extracts of Eucalyptus globule. Agri. J. 3(1): 42-45.

[14]. Elumalaii EK, Chandrasekaran N, Thirumalaii T, Sivakumari C, Viviyan TS and David E (2009) Achyranthes aspera leaf extract s inhibited fungal groth. Inter. J. PharmTech Res. 1(4):1576-1579.

[15]. Ghosh A, Das BK, Chatterjee SK and Chandra G (2008) Antibacterial potentiality and phytochemical analysis of mature leaves of Polyalthia longifolia (Magnoliales: Annonaceae). The South Pacific J. Natural Sci., 26: 68-72.

[16]. Girach RD and Khan ASA (1992) Ethnomedicinal uses of Achyranthes aspera leaves in Orissa (India). Int. J Pharmacogn. 30:113115 .

[17]. Ghani A (2003) Medicinal Plant of Bangladesh with Chemical Constituents and Uses. $2^{\text {nd }}$ ed. Asiatic Society of Bangladesh, Dhaka, p.71-72.

[18]. Hiromu S, Akira K, Tamas K, Tamas J and Masakazu H (2010) Metallo-allixinate complexes with anti-diabetic and antimetabolic syndrome activities Metallomics 2: 670-682.

[19]. Han ST and Un CC (2003) Cardiac toxicity caused by Achyranthes aspera. Vet Hum Toxicol. 45(4):212-213.

[20]. Jaber MA and Al-Mossawi A (2007) Susceptibility of some multiple resistant bacteria to garlic extract. African J. Biotech. 6: 771776.

[21]. Jehan B, Muhammad T, Huma A, Amjad I and Mohammad S (2011) Effect of different solvent extracted sample of Allium sativum (Linn) on bacteria and fungi. African J. Biotech. 10(31): 5910-5915.

[22]. Jayaweera, DMA (1980) Medicinal Plants used in Ceylon Part 2. National Science Council of Sri Lanka. Colombo

[23]. Khopde SM, Priyadarshini KI, Guha SN, Satav JG, Venkatesan P and Rao MNA (2000) Biosci. Biotech. Biochem. 64:503-509.

[24]. Liersch BA (1992) In: Haensel R, Keller K, Rimpler G, Schneider G (eds) Hagers Handbuch der Pharmazeutischen Praxis, V. Springer-Verlag, Berlin 7, pp 54-59.

[25]. Mohinder K, Thakur V and Rana RC (2005) Antimicrobial Properties of Achyranthes aspera. Ancient Sci. Life, XXIV (4): 1-6.

[26]. Manandhar NP (2002) Plants and People of Nepal Timber Press. Oregon pp. 526-7

[27]. Nadkarni KM, Nadkarni AK (1999) Indian Materia Medica - with Ayurvedic, Unani-Tibbi, Siddha, Allopathic, Homeopathic, Naturopathic and Home remedies. Popular Prakashan Private Ltd., Bombay, India. ISBN No. 81-7154-142-9.

[28]. Onyeagba RA, Ugbogu OC, Okeke CU and Iroakasi O (2006) Studies on the antimicrobial effects of garlic (Allium sativum Linn), ginger (Zingiber officinale Roscoe) and lime (Citrus aurantifolia Linn). African J. Biotech. 3: 552-554.

[29]. Perry LM (1980) Medicinal Plants of East and Southeast Asia: Attributed Properties and Uses, pp. 149-150. MIT Press, Cambridge.

[30]. Pranithanchai W, Karalai C, Ponglimanont C, Subhadhirasakul S and Chantrapromma K (2009) Cassane diterpenoids from the stem of Caesalpinia pulcherrima. Phytochemistry 70(2): 300-304.

[31]. Reuter HD, Koch HP and Lawnson DL (1996) Therapeutic effects and Applications of garlic and its Preparation. In: Garlic: the science and Therapeutic Applications of Allium sativum L. and related Species, ${ }^{\text {nd }}$ Edn., Koch, H. P. and Lawnson, D. L. (Eds), pp.135-212.

[32]. Ramesh L, Chinnappa RV and Abhay KK (2011) Potential antibacterial and antifungal activity of achyranthes aspera L. Recent Research in Science and Tech. 3(4): 53-57

[33]. Raghu HS and Ravindra P (2010) Antimicrobial activity and phytochemical study of Phyllanthus Emblica linn. Inter. J. Pharm. Stud. Res., IJPSR I(I) 30-33.

[34]. Raffauf RF (1996) A Guide to Their Discovery and Distribution. Hawkworth Press, Inc. New York. p.35.

[35]. Rao YK, Fang SH and Tzeng YM (2005) Anti-inflammatory activities of flavonoids isolated from Caesalpinia pulcherrima. J. Ethnopharmacology, 100(3): $249-253$.

[36]. Selvanayagam ZE, Gnanavendan SG, Balakrishnan K, Rao RB (1994) Antisnake venombotanicals from Ethnomedicine. J Herbs Spices Med Plants 2:45-100.

[37]. Susumu Y, Shigeo K, Norihiro H, Tsuyoshi U, Hiromichi M and Shizutoshi N (1987) Antifungal Activity of Ajoene Derived from Garlic. Applied and Environmental Microbiology, 53(3): 615-617.

[38]. Schiebinger LL (2004) Plants and empire: colonial bioprospecting in the Atlantic world. Harvard University Press: Cambridge, Mass, pp.10-17.

[39]. Sutar NR, Garai US, Sharma PG and Yadav G (2011) Pharmacognostic studies of the Achyranthes aspera leaves. Pharmacie Globale (IJCP), 5 (10): 1-3.

[40]. Teferi G and Hahn HJ (2002) Treatment of malaria in Ethiopia folk medicine. Trop. Doc. 32: 206-207.

[41]. Tang C, Chen G, Chen D, Xin H and Gao L (2009) Study on Antimicrobial Activity of Crude Extract from Phyllanthus emblica L. Fruits.Chinese J. 30(7),106-108. 
[42]. Thakur RS, Puri HS and Husain A (1989) Major Medicinal Plants of India. Central Institute of Medicinal and Aromatic Plants, Lucknow, India.

[43]. Treadway L (1994) Amla Traditional food and medicine. J. Amer. Bot. Coun. 31: 26.

[44]. Tsarong TJ (1994) Tibetan Medicinal Plants. First edition. Tibetan Medical Publications, India. ISBN No. 81-900489-0-2.

[45]. Tahiliani P and Kar A (2000) Achyranthes aspera elevates thyroid hormone level and decrease hepatic lipid peroxidation in male rats. J. Ethanopharmacol. 71: 527-532.

[46]. Torssel KBG (1993) Natural Product Chemistry. A mechanistic and biosynthetic approach to secondary metabolism. John Wiley \& Sons Ltd, London.

[47]. Ureghe UBO, Ehwarieme DA and Eboh DO (2010) Antibacterial activity of garlic and lime on isolates of extracted carious teeth. African J. Biotech.9(21): 3163-3166.

[48]. Udupa KN (2002) Ayurveda for Promotion of Health."Journal of Ayurveda, 3. Williamson EM (editor), Major Herbs of Ayurveda, Churchill-Livingstone, London.

[49]. Valsaraj R, Pushpangadan P, Smitt U W, Andersen A and Nyman U (1997) Antimicrobial screening of selected medicinal plants from India. J Ethnopharmacol. 58:75-83.

[50]. Xiaoli L, Mouming Z, Jinshui W and Wei L (2009) Antimicrobial and antioxidant activity of emblica extracts obtained by supercritical carbon dioxide extraction and methanol extraction. J. Food Biochem. 33: 307-330. 